\title{
SALUD INTERCULTURAL: IMPACTO EN LA IDENTIDAD SOCIAL DE MUJERES AIMARAS
}

\author{
Carolina Valdebenito, Marilyn Rodríguez, Andrea Hidalgo, Ulises Cárdenas y \\ Fernando Lolas*
}

\begin{abstract}
Resumen: Este artículo busca determinar el impacto sociocultural de las políticas públicas y la modernización en salud y educación en los pueblos aimaras en Chile, desde un enfoque cultural. Su intención es aproximarse al significado atribuido por las mujeres aimaras de Colchane a las políticas públicas en salud reproductiva y cómo impacta en su cosmovisión.
\end{abstract}

Nuestra hipótesis es que las mujeres aimaras no se apropian de las políticas culturales en salud reproductiva porque no responden al sentido cultural que involucra el proceso reproductivo. Este trabajo quiso indagar sobre el sentido social y la construcción valórica tras estos procesos sociales y determinar cómo afecta a la incorporación de las políticas públicas.

Palabras clave: aimara, mujer, salud, salud intercultural

\section{INTERCULTURAL HEALTH: THE IMPACT IN THE AIMARA WOMEN SOCIAL IDENTITY}

Abstract: This paper is part of a research project which tries to determine the socio cultural impact of public policies and the modernization process in the health care of the aimara ethnic group in Chile, from a cultural perspective. Its purpose is to approach to the meaning attributed by the aimara women from Colchane to the public policies related to reproductive health and how it impacts their cosmic vision.

Our hypothesis is that the aimara women do not appropriate these public policies on reproductive health as proper because they do not respond to their cultural meaning about the reproductive process.

Key words: aimara, women, reproductive health, public policies

\section{SAÚDE INTERCULTURAL: IMPACTO NA IDENTIDADE SOCIAL DAS MULHERES AIMARAS}

Resumo: Este artigo procura determinar o impacto socio-cultural das políticas públicas, a modernização em saúde e a educação nos povos Aimaras no Chile, desde um enfoque cultural. Seu objetivo é se aproximar do significado atribuido pelas mulheres Aimaras de Colchane às políticas públicas em saúde reprodutiva e como impacta em sua cosmovisão.

Nossa hipótese é que as mulheres Aimaras não se apropriam das políticas culturais em saúde reprodutiva porque não respondem ao sentido cultural que envolve o processo reprodutivo. Este trabalho quis indagar sobre o sentido social e a construção de valores através destes processos sociais e determinar como isto afeta a incorporação das políticas públicas.

Palavras chave: aimara, mulher, saúde, saúde intrcultural

* Investigadores del Proyecto CHI0R105: "Impacto sociocultural de las políticas públicas y la modernización en salud y educación de los pueblos aimaras en Chile, desde un enfoque cultural”, financiado por PNUD-UNFPA. Convenio número 06/2005.

Correspondencia: valdebec@chi.ops-oms.org 


\section{Construcción cultural del género en la cultura aimara}

"Es el género uno de los principios organizativos desde donde se piensa y construye la vida social, económica, política y religiosa de la sociedad aimara(1)".

Las diferenciaciones sobre género en la cultura aimara se definen en torno a las fases de ciclo vital de las personas y al rol social que cumplen. La construcción cultural y simbólica del género variará según el contexto relacional que cada persona vivencie. Por lo tanto, las valoraciones del rol social de cada género pueden no ser comprendidas por un extraño a su cultura y traducir el rol de la mujer aimara en su comunidad sólo como mera subordinación, toda vez que el valor cultural de lo femenino en la cultura señalada reposa en su capacidad reproductiva. Es así que las distintas interpretaciones culturales pueden dar significados erróneos.

Estas mujeres tienen una fuerte presencia en todas las actividades asociadas con la fertilidad, como son la siembra, la cosecha, la alimentación y el pastoreo de animales. "Lo femenino es fundamentalmente pensado como generativo y fértil(2)". Pero también tienen una fuerte vinculación con lo económico, siendo las encargadas del comercio y del hospedaje, es decir, del sustento de los hijos.

Respecto de su sexualidad, se debe considerar que llevan doscientos años de socialización occidental y que en los últimos diez la religión pentecostal ha producido un gran proceso de aculturación y desarraigo cultural. Por lo tanto, si lo ortodoxo en su cultura fue que la adolescencia fuese considerada una etapa para explorar la sexualidad, hoy esta cosmovisión ha cambiado con el cristianismo y, específicamente, con el pentecontalismo. Otro aspecto es que la cultura aimara no exalta el placer sexual como valor.

A su vez, la capacidad reproductiva de la mujer aimara es tan altamente valorada que, aunque surjan embarazos no previstos o fuera del matrimonio, éstos no constituyen un problema social. Consecuentemente, los hijos representan siempre un valor.

Otro aspecto que afecta la valoración de la mujer en la comunidad es que el proceso de articulación familiar es patrilocal y endogámico. Esto tiene por consecuencia la movilidad y desarraigo familiar de las mujeres a las tierras del esposo, lo que la convierte en extranjera y dependiente en una nueva familia. La translocalidad puede extrapolarse a la idea de los pisos ecológicos(3).

Entre las mujeres aimaras, hay algunas que viven en la ciudad mientras sus maridos cuidan el ganado en el altiplano (aunque la experiencia en terreno mostró que son los jóvenes y niños quienes están a cargo de estas tareas en la actualidad, debido a que los hombres se ocupan del comercio de automóviles). Algunas mujeres se quedan en el altiplano mientras los jóvenes bajan a las ciudades, o bien, los ancianos se quedan al cuidado de los nietos mientras los jóvenes migran a las ciudades en busca de fuentes de trabajo. En consecuencia, se podría proponer que la patrilocalidad es un paradigma en crisis.

Lo destacable de esta movilidad social son tres fenómenos que tienen que ver con el proceso de modernización: 1) la mujer está a cargo del sustento de la familia; 2) existe el concepto de movilidad y complementariedad ecológica de recursos, que trasciende las fronteras políticas entre Perú/Bolivia/Chile, y 3 ) en un intento por establecer soberanía política se han desarrollado políticas de integración que 
buscan promover el sentido de chilenidad en la comunidad aimara y, con ello, separarlas de las demás comunidades del altiplano.

\section{Cosmovisión del origen de la vida y embarazo}

Según los aimara, la concepción humana se produce por la mezcla del semen del hombre y la sangre de la mujer. Gavilán y Carrasco señalan que las mujeres aimaras identifican el período menstrual como el momento más fértil de la mujer.

Por otra parte, durante el período prenatal las futuras madres continúan ejerciendo sus actividades cotidianas hasta el momento de dar a luz e, incluso, recomiendan hacer el mayor número de actividades para asegurar un parto más fácil y rápido, creencias que se contraponen a las recomendaciones occidentales de evitar el esfuerzo físico que ponga en peligro el término del embarazo. La percepción de éste es totalmente distinta a la que existe en la cultura chilena: las mujeres aimaras dan a luz solas, sin ayuda médica, excepto por las parteras; el conocimiento sobre la salud puerperal es algo que manejan todas y no está restringido a alguna categoría social en particular.

Uno de los elementos que más se destaca en la cosmovisión andina -muy presente en el período de gestación y parto- es la complementariedad de las mitades y su necesidad e interdependencia: no es posible la existencia de uno sin el otro. Esta relación de opuestos complementarios se expresa durante el embarazo, al considerar que el cuerpo de la madre es "cálido" y al momento del parto hay "frío", por lo que en el período de gestación se utilizan plantas medicinales con el propósito de alcanzar el equilibrio con el entorno. Siendo lo cálido lo deseable, no gustan de adoptar los métodos de la medicina alopática, porque ser desvestidas o depiladas atenta contra el equilibrio entre lo externo y lo interno ${ }^{1}$.

Al considerar que durante el parto se enfría el cuerpo, el lugar preferido para dar a luz es la cocina, ya que el frío las hace vulnerables a diferentes males. Por otra parte, ellas frecuentemente consideran algunas de sus enfermedades como consecuencia de la maternidad.

\section{Control natal}

La importancia y valoración de la capacidad fertilizadora de la mujer se expresa incluso por medio de la sanción informal a aquellas mujeres que no pueden concebir. Igualmente, existe un entramado cultural que las disuade de hacer uso de métodos anticonceptivos. Sin embargo, esto también debe ser observado a la luz de la influencia pentecostal, que está en contra de las prácticas abortivas o anticonceptivas.

Sin embargo, ciertas tendencias analíticas relacionan la opresión de las mujeres y su papel reproductivo con la falta de uso de anticonceptivos. Según esas tendencias, los hombres buscarían así evitar posibles infidelidades de sus mujeres mientras ellos no están. Estas concepciones parecen no considerar, sin embargo, las diferentes construcciones sobre los roles de género en los pueblos indígenas.

Las tasas de fecundidad demuestran que, dentro de su cultura, la planificación familiar no está totalmente integrada. Aunque se practican diferentes métodos anticonceptivos, naturales y no validados por la ciencia, o distanciamiento entre embarazos, no existe una aceptación pública de la tecnología anticonceptiva y su

1 Esto se explica, pues la duplicidad está presente en toda la cosmovisión de los grupos del altiplano, desde el imperio Tiwanaku. La partición del mundo en dos mitades implica que lo que un día está arriba -poderoso, fuerte y viril-puede luego estar abajo -débil, pasivo, femenino-, lo que es absolutamente opuesto a la dominación de un rol sobre otro. 
etno-conocimiento al respecto es desplazado por los preceptos de la iglesia pentecostal, de la cual en su mayoría son fieles.

No obstante, las estadísticas sociales de los pueblos indígenas en Chile muestran que los niveles de fecundidad han disminuido. Al comparar las mujeres indígenas de zonas urbanas con las que habitan en zonas rurales, estas últimas tienen, en promedio, un hijo más que las primeras. ¿Qué demuestran estos cambios en las tasas de embarazos? ¿Han sido incorporados los métodos de control natal impulsados por las políticas públicas a pesar de las limitantes culturales y sociales?

\section{Política indígena chilena}

Los aimara han experimentado un proceso de chilenización, sin considerar las diferencias culturales, desde la Guerra del Pacífico (en 1879) hasta el fin de la dictadura militar (1990 aproximadamente). Antes del conflicto, la actual Región de Tarapacá pertenecía a Perú y parte de la Región de Antofagasta a Bolivia. Esto es, sin esa guerra la incorporación de este grupo a la idiosincrasia chilena no habría existido.

Junto con la elección del primer gobierno democrático en Chile, luego de la dictadura militar, se genera un conjunto de leyes que amparan a los grupos indígenas y buscan la integración de las diferencias culturales. En este período se pudo apreciar una valoración del multiculturalismo debido a la influencia ejercida por nuevas corrientes mundiales: Amnistía Internacional, Ley de los DD.HH. (Convenio 169 OIT), entre otros.

A su vez, durante los años 90 surge una nueva estructura estatal que busca incorporar a los marginados a través de programas especializados, como son SERNAM (Servicio Nacional de la Mujer, 1991), FONADIS (Fondo Nacional de Discapacidad, 1994), CONADI (Corporación
Nacional de Desarrollo Indígena, 1993), FOSIS (Fondo de Solidaridad e Inversión Social, 1990), e INJUV (Instituto Nacional de la Juventud, 1991), todas organizaciones bajo la tutela de MIDEPLAN (Ministerio de Planificación y Desarrollo). Cabe resaltar el papel de CONADI y de su Programa Orígenes como un valioso instrumento para el desarrollo de las políticas estatales en materia de derechos originarios.

El Programa de Salud Intercultural del Programa Orígenes tiene como objetivo mejorar las condiciones de vida de la población indígena por medio de reformas al acceso a servicios de salud y la integración de la medicina indígena(4). Un ejemplo del esfuerzo integrador es la formación en salud de "facilitadores" que, siendo miembros de los grupos indígenas, conocen la lengua vernácula, pero también han estudiado y han estado en contacto con la sociedad moderna; de esta manera logran manejar la duplicidad de los códigos culturales. Estas personas "facilitan", por tanto, la comunicación con los miembros de los grupos indígenas que no manejan la lengua española, o que no comprenden los códigos burocráticos de los sistemas públicos modernos.

\section{Conclusión}

La apropiación de las políticas culturales en salud reproductiva por parte de las mujeres aimaras se ve interferida por las condiciones de infraestructura: la posta de Colchane carece de un médico alopático o de servicios básicos de urgencia que incentiven y den confianza a la población. En consecuencia, es habitual escuchar que prefieren ver a la partera, pues ella controla y vigila sus embarazos.

En otro sentido, es claro que el sistema de salud trata de incorporar a la población indígena, haciendo un esfuerzo por acercarse y establecer puentes de comunicación. El dilema se presenta cuando, aun existiendo las formas 
de integración, no existe el fondo. Por ejemplo, el Programa de Parto Aimara es un gran esfuerzo de profesionales y del servicio de salud de la zona, en Iquique; pero las mujeres aimaras no tienen gran adherencia al programa pues, aunque este comprende la forma en que se debe producir el parto, no tiene el simbolismo social que se da en la comunidad.

A su vez, el distanciamiento -que por momentos dificulta el acceso a la "modernidad"- es también lo propio de su cultura: es la distancia física, en complementariedad con la trashumancia. Ya se ha hablado del factor de traslocalidad del pueblo aimara: ellos son portadores de su cultura con independencia del lugar en que se encuentren, por lo tanto, sus fronteras culturales chocan de igual modo con los agentes externos, ya sea que estén en zona urbana o rural.

"La mujer aimara prefiere el trato personal en la seguridad de su casa, la conversación en su propia lengua y la comprensión y la importancia que le da a su mundo espiritual el especialista local. Ella evita así la vergüenza de los exámenes vaginales, la posición incómoda para dar a luz en el hospital, las prácticas de higienes rigurosas que contradicen a la prescripción tradicional del baño parcial sólo después de una semana del parto o el baño completo luego de un mes, además del gasto que significa llegar al hospital(5)".

Las diferencias lingüísticas juegan un papel muy importante en el distanciamiento de los centros hospitalarios. Aunque la comunidad es bilingüe casi en su totalidad, las mujeres buscan la comodidad de un ambiente familiar donde puedan hablar su propia lengua. Si la mujer indígena no puede expresar adecuadamente sus síntomas y, a su vez, el médico no puede darse a entender apropiadamente, se crean barreras culturales que tienen un impacto en el diagnóstico y tratamiento sanitario, lo cual puede crear una mala disposición hacia el servicio médico. Las mujeres prefieren dar a luz en su casa, porque ahí encuentran el apoyo psicosocial y la familiaridad que los hospitales no les ofrecen. En estas comunidades es frecuente que el esposo esté presente durante el parto, lo que no sucede en hospitales públicos.

Frente a la aversión por asistir a los centros médicos oficiales y a la preocupación por los sistemas públicos de fiscalizar todas las operaciones y acciones sociales, es que las políticas públicas han hecho esfuerzos por atraer a las mujeres y manifestar su deseo de integración, siempre que sea en un lugar autorizado, sanitizado, según los cánones occidentales ${ }^{2}$. En este punto radica entonces el dilema social de apropiación de políticas públicas.

Sin duda que el ethos cultural(6) aimara se ha visto modificado por la apertura al mundo globalizante. Sería ingenuo de nuestra parte esperar que las comunidades estuviesen estáticas en su ethos cultural. La cultura aimara está totalmente integrada; conoce los códigos del mercado y la forma de transar y de comerciar; no se puede esperar conocer grupos aislados $\mathrm{y}$ huérfanos de modernidad.

En Colchane, la comunidad de estudio en este trabajo cuenta con servicios básicos idénticos a cualquier pueblo rural de Chile y con iguales limitaciones de infraestructura. Los dilemas antropológicos, por lo tanto, tienen que ver con el sentido de esta integración. Las mujeres aimaras, a cargo del sustento económico y moral de las familias, son quienes comercian, se asientan en la frontera con Bolivia a vender víveres a los transeúntes y administran

2 "Desde el 9 de julio de 2006, el Hospital de Iquique, en la zona norte de Chile, cuenta con una sala especialmente adornada con motivos propios de la cultura aimara para que ellas den a luz de la forma que más les acomode (de pie, acostadas sobre una cama normal, sentadas en el piso o en una mesa ginecológica)". Agencia Servicio Especial de la Mujer, SEM. 
hosterías, mientras los hombres salen tras el comercio fronterizo de autos y drogas. Ellas tienen un concepto más capitalista que los románticos del capitalismo, pues se incorporan a la economía de mercado y conocen muy bien los códigos de la modernidad, en un pragmatismo prosaico. No existe el conflicto por la ganancia o la maximización de recursos.

La aculturación se produce con la incorporación de la iglesia pentecostal, que parece más estricta que la Iglesia Católica. La rigurosidad de esta iglesia no da cabida el sincretismo religioso del que fue parte el catolicismo. El protestantismo aleja a los aimaras de su identidad étnica, de sus valores indígenas, dado que tales etnoconocimientos son considerados hechicería. Frente a este código estricto, el laicismo de un Estado modernizador trata de implementar medidas de control natal y se encuentra con un muro de resistencia significante.

Los aimaras son una cultura que ha cambiado: ya no son los descendientes del imperio
Tiwanaku, son aimaras modernos, híbridos, cristianos, donde habita la moral de los opuestos complementarios y la rigurosidad de un cristianismo que rechaza las duplicidades.

Frente a esta realidad, el éxito de las políticas sanitarias dependerá no sólo de la integración de elementos culturales, a la usanza de un museo o un collage; no sólo de resucitar elementos culturales. El éxito de la incorporación y apropiación de la modernidad por parte de las mujeres aimaras descansa en la producción de una red semántica, en la cual se inserten procedimientos con sentido cultural y no desarraigados del contexto.

\section{Agradecimientos}

Artículo producido con los resultados del Proyecto CHI0R105: "Impacto sociocultural de las políticas públicas y la modernización en salud y educación de los pueblos aimaras en Chile, desde un enfoque cultural", financiado por PNUD-UNFPA. Convenio número 06/2005.

\section{Referencias}

1. Carrasco AM. Constitución de Género y Ciclo Vital entre los Aimara Contemporáneos del Norte de Chile. Chungará 1998; 30(1): 87.

2. Gavilán V. Buscando Vida: Hacia Una Teoría Aimara de la División del Trabajo por Género. Chungará 2002; 34(1): 114.

3. Murra JV. El mundo andino: población, medio ambiente y economía. Lima: Instituto de Estudios Peruanos; 2002.

4. Programa Orígenes. Estudio Linea de Base en Comunidades Indigenas: Primera Fase. Santiago de Chile: Departamento de Economía, Universidad de Chile; 2003.

5. Defossez A, Bassin D. El Embarazo en Mujeres Aimara Migrantes. En: Mujeres de los Andes: Condiciones de Vida y Salud. Bogotá: Instituto Francés de Estudios Andinos; 1992: 128.

6. Morandé P. Cultura y modernización en América Latina: ensayo sociológico acerca de la crisis del desarrollismo y de su superación. Madrid: Encuentro; 1987. 


\section{Bibliografía}

Albo X. Aimaras entre Bolivia, Perú y Chile. Estudios Atacameños 2000; 19: 43-73.

Gundermann H. Sociedad aimara y procesos de modernización durante la segunda mitad del siglo XX. Santiago de Chile: Comisión de Verdad Histórica y Nuevo Trato; 2002.

Grebe Vicuña ME. Antropología cultural del pueblo aimara. Santiago de Chile: BAFONA; 1989.

Tudela P. El Estado y sociedad chilena ante los aimaras de Tarapacá (I Región de Chile). Santiago de Chile: Comisión de Verdad Histórica y Nuevo Trato; 2002.

Recibido el 23 de mayo de 2006.

Aceptado el 22 de junio de 2006. 